\title{
Paper Waste Recycling. Circular Economy Aspects
}

\author{
Zanda U. OZOLA ${ }^{1 *}$, Rudite VESERE ${ }^{2}$, Silvija N. KALNINS ${ }^{3}$, Dagnija BLUMBERGA ${ }^{4}$ \\ ${ }^{1-4}$ Institute of Energy Systems and Environment, Riga Technical University, \\ Azenes iela 12/1, Riga, LV-1048, Latvia
}

\begin{abstract}
Paper waste is a raw material for a lot of products with different added value. The engineering, economic and environmental aspects of paper waste recycling are analysed for production of composite material, cellulose nanofibers and nanocrystals, bricks with paper components, porous carbon, film of biopolymer, enzymatic sugar and bioenergy: bioethanol, hydrogen and biofuel. Through multicriteria analysis, it was possible to determine the most feasible paper waste recycling product in case of four product groups: egg packaging boxes, cardboard, reused paper, cellulose nanomaterials (nanofibers and nanocrystals). The production of cellulose nanofibres and cellulose nanocrystals has an advantage over egg packaging and cardboard production as well as reusable paper.
\end{abstract}

Keywords - Bioenergy, bioethanol, biofuel, cellulose nanofibers and nanocrystals, enzymatic sugars, film of biopolymer, hydrogen, paper, paper waste, paper waste bricks, porous carbon

\section{INTRODUCTION}

Paper and cardboard account for a large share of total waste - about $10 \%$ of total municipal solid waste. Paper is made of cellulose fibers, which are combined with a number of chemicals that determine the properties and quality of the paper, as well as chemicals, are added for bleaching the cellulose. Cellulose is a renewable natural biopolymer that is considered to be one of the most important organic compounds and it can be obtained and biosynthesized from plants, wood, sea animals, bacteria and fungi [1]. Nowadays the cellulose, which is needed to make paper, comes from wood or is extracted from waste paper, and in addition to cellulose and chemicals, paper also requires a large amount of energy as well as water. Raw materials, which are needed to produce cellulose, are renewable resources - timber and water. In the process of paper production, as well as in order to increase the quality of the product, various additives are needed, while cellulose needs to be bleached to produce quality printing paper [2]

As already known, paper and its waste are easily degradable in nature and recyclable; fibers of cellulose can be recycled up to seven times. Therefore, it is necessary to recycle useful paper waste [3]. Resources are saved for example - trees, water, oil, electricity, and also area of the landfill - if paper is recycled [4].

Over the last 40 years, paper consumption has increased by $400 \%$ globally, leading to deforestation, and $35 \%$ of felled trees are used to produce paper. The major contributor to the global economy is the paper industry; however, research shows that the paper industry offers a low profit margin and high initial investment. One of the factors in the current economic situation is the competition to meet customer requirements, which affects the profit margin. If a company manufactures a product, pricing decisions are driven by various factors

\footnotetext{
* Corresponding author.

E-mail address: zandaozola9@gmail.com
} 
such as the initial cost of equipment, labour, raw materials, and also tran sport. That is why all industries are facing one of the most common problems - pricing. In addition, the paper industry is under constant pressure - to minimise adverse emissions to water and air. Therefore, the paper industry is engaged in cost forecasting and also in manufacturing efficiency and impact on the environment due to the raw materials and processes used in production [5].

The kind of paper on the market ranges from soft paper for writing and printing to cardboard for storage and packaging. Cardboard is mainly produced from waste paper. It has a high strength and provides resistance to degradation, and therefore is notably valued in the packaging industry. Cardboard boxes are the main source of resources in the packaging industry. The demand for cardboard packaging in this sector has been around 46 million tonnes per year in Europe alone (now more) since 2007, where 228 million ton nes of recycled paper was consumed worldwide. Cardboard recycling is economically and ecologically sustainable because large quantities of paper can be produced using less energy and raw materials. Cardboard is produced just like soft paper. First, the waste products are disassembled in their individual components and materials using a sequence of production procedures. Thus, the acquired functional materials and components are washed before reuse in the production line. And at the end of the process, a new product is produced by combining refurbished parts and materials and substituting non-functional components with similar new ones.

\subsection{Recycling Waste Paper in the World}

On average, $58 \%$ of paper waste is recycled in the world. In some of the more developed countries, recycling of waste paper has even increased to $70 \%$ to $75 \%$ of the total amount of waste paper in that country. By improving the waste recycling infrastructure, these developed countries could achieve a higher percentage of paper recycling in the country, thus also increasing the global average percentage of paper recycling [6]. Europe has the highest paper recycling rate in the world; North America is ranked second, while Asia, Latin America and Africa have the lowest recycling rates globally. In Europe, paper is recycled the most after the amount of processing, followed by metal and glass and aluminium is in third and fourth [7].

Europe has set a target of recycling $74 \%$ of paper waste in Europe by 2020, already in 2017 $72.3 \%$ of total paper waste in Europe was recycled, and $72 \%$ in 2016 . However, the difficulty in achieving the goal is due to the high demand for paper packaging as well as the increasing demand for packages with more compounds, such as beverage packages which contain paper, plastic and aluminium. It should also be considered that there is paper waste that cannot be recycled, such as coffee filters and sanitary napkins. By considering these non-recyclable wastes, theoretically it is estimated that the maximum percentage of recycling is $78 \%$ rather than $100 \%$. Therefore, the greater the demand for more complex packaging, the more attention should be paid to sorting of waste [8], [9].

The European declaration about sorting paper will continue to introduce measures to optimize activities from the beginning of paper production until its use, collection and recycling to ensure that paper is recycled and its production-conversion cycle is more productive. Priority is given to the prevention of waste, as well as to the environmental impact of the paper and cardboard production process, also to the collection and recycling of these products. Of course, in exceptional cases, where recycling is not possible, other options from the hierarchy of waste may be considered. These kinds of measures ensure that the amount of paper-based waste, which usually is disposed in a landfill, will be reduced and, where it is 
possible - recycled. Particular attention will also be paid to improving the recyclability of paper products and, where it is appropriate, their applicability.

Combining these two goals and efforts to improve paper quality for recycling, can also help strengthen the importance of sorting paper and make already used paper the main raw material for the paper industry. By dividing the recyclable paper waste by its characteristics and comparing it with the characteristics of the desired end product, it would be possible to recycle paper waste more efficiently. Also, the direction of high recycling levels should be considered while respecting environmental laws.

As it is previously mentioned, the difficulty of implementing this recycling system is both non-recyclable waste and complex but paper-based packaging. There are also paper products that are collected after recycling but reused outside the recycling cycle [9].

\subsection{Recycling Process of Paper}

In companies that recycle paper waste, these pre-formed bales are divided and soaked in large containers where the paper breaks down into fibers. Various substances are added to this process to prevent ink and printing ink particles from sticking to the fibers anymore. Clay, which is attached to the paper production process, also helps to separate the printing colours and ink in the paper recycling process.

After paper is cut into fibers, it is deinked. Deinking is a process where in multiple cycles special cleansers removes admixtures such as paper supplements, coatings, ink, etc. In order to improve the white and purity of the paper on the printing paper, the cellulose is deinked in the refilling plant, it means that calcium soap is added to the liquid of cellulose and is blown through it. Hence, the dyes stick to the air bubbles and, when they rise to the surface of the liquid, form foam, which is then dropped and scooped. When dyes are removed, fibers are bleached with hydrogen peroxide. The process, where fibers are gradually cleaned, deinked from topographic paints, sieved and filtered, is repeated several times until they are suitable for production of recycling paper.

Admixtures of paper waste (glue, staples and paper clips) sink. This layer of deposits is then incinerated or landfilled. Due to the fact that cuttings of white paper either do not need cleaning or are needed in small quantities, these cuttings can be used as cellulose substitutes. The recycled cellulose is then sent to the preparation section of raw material, where it is treated like wood chips from which new paper is produced. And every time when the paper is recycled, fresh wood fiber cellulose is added due to the limited number of recycling cycles, as the mechanical and printing properties of the material deteriorate every time it is recycled because the length of the wood fibers decreases every time it is recycled [10], [11].

Beverage packaging, which consists of thin layers of plastic and aluminium, is recycled differently. Plastic and aluminium add features such as elasticity to this type of packaging and do not allow changes in the environment to affect packaged products, and stop the ability of air and other bacteria in the outside environment to enter the packaging and affect it.

These packages, which contain both aluminium and plastic, are placed in water tanks where the paper, which is contained in these packages, dissolves or decomposes into cellulose fibers and separates from the plastic and aluminium layers. Further, this cellulose, which contain cellulose fibers, plastic and aluminium, is passed through a filter that only passes through the cellulose fibers, while aluminium and plastic remain behind the filter. Further fibers are recycled, as previously it was mentioned, but aluminium and plastic are divided and transported for further processing [12]. 
Recyclable waste paper can be used for various usable paper products such as newspapers, napkins, office and printing paper, envelopes, cardboard boxes, wrapping paper, egg packaging, wallpaper, wool for thermal insulation and other products [2].

In the Netherlands, the impact of paper recycling on energy and $\mathrm{CO}_{2}$ emissions was studied. The study looked at the production of newspapers, paper for printing and writing, sanitary paper, corrugated cardboard, grey cardboard, flexible cardboard, and their main use after production [13].

Paper for newspaper can be made from primary and secondary fibers. Primary fibers are predominantly machined but recovered fibers are deinked and dispersed to obtain a higher degree of paper whiteness. The fiber composition in newsprint is $80 \%$ recovered and $20 \%$ mechanically recovered. The paper, which is used for printing and writing, consists of $100 \%$ chemically treated fibers. High quality printing and writing paper is used, for example, for magazines, which means that primary fibers are needed. This quality is related to the end product because consumers require a certain quality of whiteness and brightness. This quality is obtained by chemically treating cellulose. Sanitary paper can be produced from both primary fibers and recovered cellulose fibers. The category of sanitary paper includes, for example, toilet paper, paper handkerchiefs, disposable kitchen towels. Primary fibers are usually treated chemically. The end product of the sanitary paper must be strong, absorbent and soft. Mostly, this type of paper consists of $95 \%$ recovered and $5 \%$ chemically treated cellulose fibers [13].

Corrugated cardboard can consist of various combinations of the layers and sheets, which are produced from recovered cellulose fibers as well as mechanically and chemically treated cellulose fibers. This type of paper has a wide range of applications, but is mostly used for packaging. For the production of corrugated paper $100 \%$ recovered cellulose fibers are used. Grey cardboard, as well as corrugated cardboard, is made from $100 \%$ recovered fibers and also has a wide range of applications, such as book covers, food boxes or trays, egg packages. Because of its use, grey cardboard does not require ink removal, so it is grey. Folding cardboard can be made up of different types of cellulose fibers and is usually used for a variety of food packages. In the Netherlands this paper product consists of recovered and mechanically processed cellulose fibers. Because of its use, the outer layer must be representative, therefore cellulose fibers for these layers are either deinked or bleached, but for other layers it is not necessary. Folding cardboard consists of $66 \%$ recovered cellulose fibers and $34 \%$ mechanically processed cellulose fibers [13].

Due to growing concerns about environmental issues, it becomes important for producers to add more value to their products, at the same time reducing environmental impact. Recyclable material and recycled products are two approaches to limit environmental impact. Recycling ensures the reuse of components and materials, while secondary production retains its form and adds value to renewable products. However, the process of recycled waste paper is not possible and can in fact be called paper recycling. Recycling means changing the use of a product from its original intended use. It can be as simple as taking waste paper and converting it into notebooks, maps, etc. Renewal of recycled paper includes refining, deinking and decolourization of cellulose [5].

More and more research is being made on how to recycle used waste paper and it is discovered that cellulose is a rich natural polymer, which consists of amorphous and crystalline components. In recent years, some successful research in the industrial industry have been conducted, leading to the use of cellulose nanofibres (CNF) and cellulose nanocrystals (CNC) to achieve higher added value. Paper waste is also used to extract the previously mentioned $\mathrm{CNF} / \mathrm{CNC}$ and to make poly-hydroxy alkane (PHA), carboxymethylcellulose and polymer composite matrix. In parallel, materials, which are 
prepared from synthesis of paper waste to produce high-performance electronic components such as supercapacitors are also considered [14].

Cellulose nanocrystalline is obtained from cellulose, it contains amorphous substances known as hemi-cellulose and can be separated by mechanical grinding or hydrolysis, creating a highly crystalline or semi-crystalline structure and elasticity of the modulus can even reach $137 \mathrm{GPa}$. Cellulose nanocrystals can be obtained from waste paper such as old or recycled newspapers, old corrugated containers, waste paper of the office. Cellulose can be obtained by pre-treatment of waste paper with sodium hydroxide $(\mathrm{NaOH})$ to remove hemi-cellulose with bleach, and cellulose needs to be treated with sodium hypochlorite $(\mathrm{NaClO})$ to remove lignin. Nano-cellulose crystals can be prepared using a repeated sulfuric hydrolysis method or enzymatic hydrolysis. The obtained cellulose nanocrystals were compared, some were obtained from waste paper, but other samples - from materials such as cotton, tunicates, bacteria and sisals [14].

After the grid of nano fiber was prepared, the materials were studied. Characteristics of these fibers were studied - fiber size and mechanical properties, as well as microscopy of atomic forces. The chemical composition of both: the dry and the wet fraction of paper sludge were the same because they were obtained from one factory [15].

Paper waste recycling technologies are applied for production of different materials (Fig. 1).

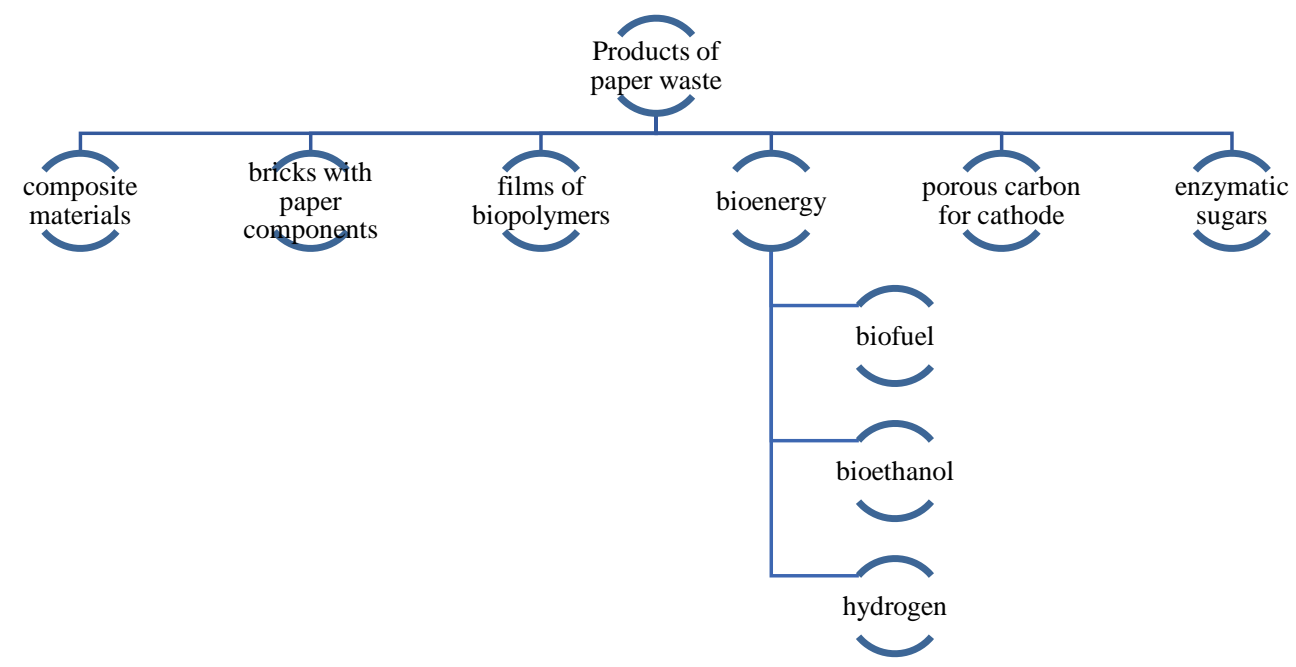

Fig. 1. Products from paper waste.

- Cellulose fibers are commonly used as reinforcement materials in composite materials because they provide high tensile strength and other material properties. Waste paper (WP) was used as a filler in samples of polyester (P) and polyurethane (PU) at a ratio of 20:80. The tensile strength of the sample, which consists of polyester and waste paper (P/WP), decreased, but its module increased. However, in another study where the ratio of polyethylene to paper waste was 50:50, it was observed that the tensile strength in this sample increased by $30 \%$, which indicates that there is an optimum point for adding waste paper. In the polymer composite paper particle, adhesion can be improved by processing the polymer. Low density polyethylene, which is treated with maleic anhydrite and bonded with composites of waste paper, shows significant tensile strength $(88 \%)$ and modulus 
elasticity (409\%). Cellulose nanocrystals from 20 to $60 \mathrm{~nm}$, which are obtained by hydrolysis of paper waste, were used to replace black hydrocarbons in reinforcement of natural rubber (NR), and had little effect on mechanical properties and as well improved the recycling properties of natural rubber. Inorganic ingredients in recycled paper such as kaolin clay and precipitated calcium carbonate (PCC) were replaced by cellulose nanofibers with higher burst and tension strength. Waste paper is also incorporated into building materials such as concrete, mortar, brick and cement composites [14];

- Bricks with paper components were created and these bricks were compared to the basic properties of conventional bricks. Basic features - must be the same colour, with smooth surfaces, no cracks and with sharp and defined edges. They need to be so solid that they do not get any dents by scratching with nails and create a clear ringing sound, when colliding with each other. They should also have a low thermal conductivity and a water absorption percentage of less than $20 \%$ if they are soaked in cold water for 24 hours. Ordinary bricks in the durability test break in half, but the paper-made bricks in this test were elastic when only half of the force was applied to them, but when they were tested at full-load, the exterior of the brick was broken, so it was concluded that they would not be suitable for main construction, but could be an alternative to additional structures. Therefore, it can be said that bricks containing paper particles can be a new solution for environmentally friendly buildings [16];

- Films of biopolymer cellulose nanocrystalline have high transparency, low weight, biodegradability, and barrier properties that are suggested in packaging. Transparent cellulose nanocrystals (CNC) films, which are made from office waste paper, were used to cover polyethylene terephthalate (PET). Coating with CNC improved water vapor barrier and was considered as useful to extend the shelf life of packaged foods. Comparing the different films, it was observed that some of those that were darker had better permeability $(65 \%)$ than those that were lighter $(59 \%)$. Films of composite of sodium alginate/carboxymethyl cellulose were produced from waste paper. And although the tensile strength (2 MPa) of the film was lower than low density polyethylene (LDPE) and high-density polyethylene (HDPE), the resulting materials were considered appropriate for low mechanical packaging [14];

- Hybridization of lithium-ion batteries with electro-chemical capacitors require the use of high-carbon materials such as graphene, activated carbon and also activated carbon from the biomass for electrode material. Such Lithium Ion Hybrid Electrochemical Capacitors (Li-HEC) are considered as a potential source for more efficient energy storage systems. Porous carbon, which is obtained from hydrothermal treatment and pyrolysis of office paper, was used as a cheap source of cathode material for Li-HEC. Waste paper, that is transformed into composite paper (GCCP) of graphene and carbon fiber, shows high conductivity and electrochemical stability to electrodes. Elastic supercapacitors were obtained by anchoring reduced graphene oxide-manganese dioxide $\left(\mathrm{RGO}-\mathrm{MnO}_{2}\right)$ on office papers. The obtained material showed an energy storage capacity of $19.6 \mathrm{Wh} \cdot \mathrm{kg}^{-1}$ and was initiated to be used in electronic devices. Cyanoethyl cellulose, which is derived from waste paper can also be used for organic field electric transistors (OFET), because such organic components attract attention to their low cost, ease of processing, flexibility, and light chains suitable for very low power electronics applications such as radio frequency identification (RFID), markers, biodegradable electronics for medical implants, sensor devices, etc. In recent years the most advanced hybrid devices are the most promising storage systems for large-scale smart networks and industry applications. Compared to secondary batteries, Li-HEC has high energy density, high power and long-term stability. 
Generally, Li-HEC is made of double-layer electric materials such as positive electrode (component of supercapacitor) and lithium as negative electrode (lithium ion battery);

- Enzymatic hydrolysis of office paper waste produces enzymatic sugars, which are used in the preparation of poly (3-hydroxybutyrate) (PHB) and is a short chain length from polyhydroxyalkanoate (PHA). Polyhydroxyalkanoates (PHA) is a biodegradable polyester, that is derived from microorganisms synthesized in the presence of elevated carbon. Although PHA has limitations compared to synthetic plastics, which include high production costs, compatibility with old processing methods and the possibility of thermal degradation, however improved mechanical properties have been found when it is mixed with other polymeric materials or modified chemically [14];

- The potential of waste paper biofuel will replace up to $5 \%$ of fossil fuels. Recent studies on the use of paper waste as a raw material for various forms of energy production such as ethanol, hydrogen, methane have shown hopeful results. Waste-paper is used as raw material for anaerobic dissolution to produce bioethanol and methane using enzymatic hydrolysis. Enzymatic hydrolysis uses enzymes to break down cellulose and lignin, which are producing reducing sugars such as glucose, and glucose fermentation produce bioethanol, which can also be converted to methane. The efficiency of the hydrolysis process with respect to glucose release is influenced by expensive enzymes and long retention time. It has been observed that pre-treatment methods improve the result of the process. Pre-treatment disrupts the crystalline structure and increases the surface area. It improves the availability of enzymes to cellulose and reduces the enzyme load. The studies evaluated chemical and physical pre-treatment techniques to demonstrate their effect on glucose excretion after enzymatic hydrolysis of waste paper. Another study found that prior to enzymatic hydrolysis, mechanical pre-treatment of paper waste with Hollander beater increased the amount of methane in anaerobic digestion by $21 \%$ in $254 \mathrm{ml} / \mathrm{g}$ of solid volatile substances, Nishimura reported a higher methane content of $270.5 \mathrm{ml} / \mathrm{g}$ solid volatile substances, if yeast is added before grinding and fermentation [14];

- Bioethanol can also be obtained from paper recycling sewage, which is usually deposited in landfills because of the limited number of treatments, but it also contains a significant amount of sugar that can be used to produce other products such as bioethanol or lactic acid. As well as from an economic point of view, recycling of such paper and production residues could be developed on an industrial scale. However, although enzyme producers have made progress, the cost of enzymes is still a significant part of the final cost of ethanol. For this reason, research is being conducted to reduce these costs, unfortunately the number of studies on the recycling of enzymes are very few. There is also little research done to evaluate the converted paper sludge material and apply a filtration process to it, giving it even more importance, as these processes are usually costly [17];

- Hydrogen is a clean source of fuel because it does not emit contamination during combustion. Organic hydrogen production, where dark fermentation is used, is less energyintensive than conversion of hydrocarbon vapor and water hydrolysis. It has been shown that the fermentation of sugar, that is obtained from the hydrolysis of paper waste acid, produces hydrogen gas. However, limits of hydrogen production delay of the fermentation process, which is caused from the hydrolysis of acid.

\subsection{Economic Evaluation of Paper Recycling}

From an economic point of view, research has shown that recycling can bring more profit for the development of new products. From an environmental point of view, recycling and retreatment help to reduce effect on environment, as it prevents waste after consumption and 
requires fewer natural resources, thus prolonging the life time of the product. In general, recycling and retreatment will have an impact on sustainability, namely the economy, the environment and society. Thus, it can be concluded that the recycling and retreatment of products is not only economical but also environmentally friendly. Pollution emissions for example from heat and surface treatment, can occur in processes such as recycling, improvement and retreatment. However, when waste is being reused, the level of harmful emissions is reduced compared to the production of raw materials, which can also improve the sustainability of products [5].

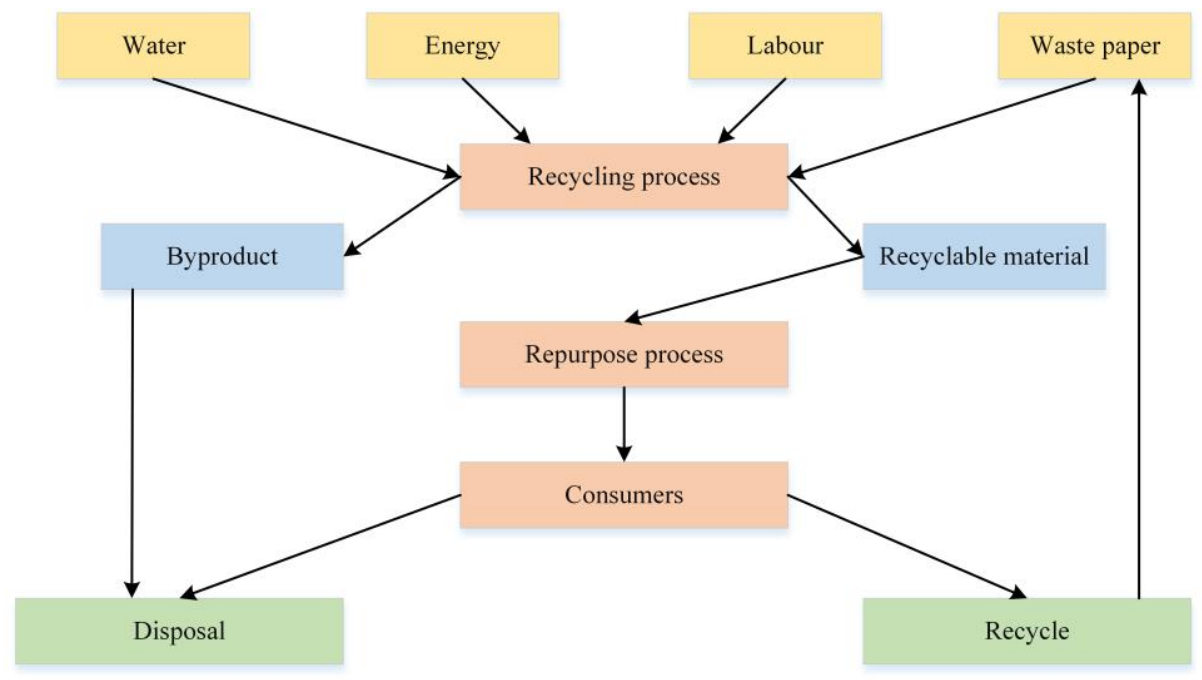

Fig. 2. Scheme for recycling paper and recycling cost estimation.

Approach of cost modelling, which is used to predict or estimate the future cost of a production good or service, is based on facts and figures which are currently available. Approach of cost modelling is also considered an important management tool in the first stages of product planning and manufacturing as it helps to determine the budget for resource allocation. It also helps the industry to predict the financial impact and the cost to projects and also alternatives. Cost estimation is crucial for any business, as even a small mistake in cost estimation can lead to losses, thus affecting the company's sales and profits. Therefore, cost estimation is an important task in the life cycle of a product. Initially, little attention was paid to the evaluation of the costs of end-of-life products in the research community, but this focus is now on. Thus, a system has been developed to predict the cost of depreciation, thus creating a more environmentally sustainable product and higher profits.

Costs occur at different stages of production from raw material collection to production or recycling to the end product and from further waste from the process of recycling, purification or landfill. The initial costs can be divided into categories: costs of raw material and energy, purification and waste removal costs, labour costs [5].

Since the models of cost are flexible, they can be applied to all industries which are involved in the recycling and sorting of paper and cardboard waste. Paper manufacturers will always consider recycled paper waste as it is environmentally and economically beneficial. In the real world, production factors change every day. Therefore, to practically apply the cost equations the input data or parameters have to be changed continuously. 
However, the estimation of the cost of recycling and recycling paper waste cannot be fully achieved without complete data in even one of the sectors because these calculations are no longer accurate, but only provisional. Also, in this research the calculations could not be fully performed due to the small amount of data and therefore, the study should be repeated or made in-depth, supplementing the data to make the results more accurate. In order to make the study more accurate, it is necessary to develop methods to assess the speed and quantity of production and the reusable amount, that can be produced, considering the quantity of certain raw materials and other important factors of production. The study should also include uncertainty in order to achieve a realistic result. The analysis of the data should also be carried out for at least one month in order to investigate the significant overall impact and could also compare the obtained data with some other paper producers [5].

\subsection{Environmental Impact of Paper Production}

Environmental pollution in the industry of cellulose and paper is mainly due to preparation and bleaching processes of cellulose. Sulphur compounds from 0.5 to $30 \mathrm{~kg} / \mathrm{t}$, nitrogen oxides from 1 to $3 \mathrm{~kg} / \mathrm{t}$, volatile organic compounds $15 \mathrm{~kg} / \mathrm{t}$, and dust from 75 to $150 \mathrm{~kg} / \mathrm{t}$ are released in the air. Waste water can be contaminated with chlorine compounds, nitrogen and phosphate compounds and various organic compounds, and heavy metals. If chlorine compounds are not used in the bleaching processes, black liquors are formed.

Primarily the environmental impact by recycled paper is emissions in water, solid waste, if in colour purification is used rinsing, and emissions in the atmosphere. Emissions to the atmosphere are linked to the production of energy when fossil fuels are burned in power plants. Most recycled paper factories are combined with paper mills.

Recycling paper saves wood resources, which provide both a home for living organisms and help to regulate the climate, as a medium-sized tree absorbs about $6 \mathrm{~kg}$ of $\mathrm{CO}_{2}$ per year. As well forests absorb and/or delay excessive moisture, but in dry weather they are able to give refreshment. Paper recycling reduces emissions of $\mathrm{CO}_{2}, \mathrm{NO}_{2}$ and $\mathrm{SO}_{2}$ in the air, and reduces water pollution with chlorine compounds from bleaching and chemicals [2].

\section{Methodology. Multi-Criteria Analysis}

Multi-criteria analysis is done to find out which of the offered options is the most successful, most beneficial. This method is designed to improve the quality of decisions by involving several criteria in the decision-making process to make choices clearer, more rational and more effective. This analysis is used for a number of purposes, such as identifying the best alternative or evaluating alternatives. This multi-criteria method is TOPSIS.

The process of multi-criteria analysis is based on the principle of graduality and involves five steps - selection of criteria, data entry, application of the method, acquisition and analysis of the result (Fig. 3).

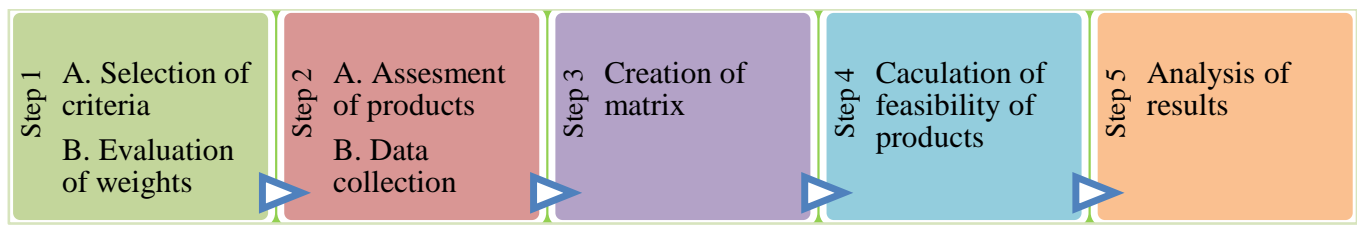

Fig. 3. Step-by-step methodology. 
The selection of criteria is based on an approach that includes the widest possible variety of aspects into the analysis. The criteria have been modified so that they can be compared with each other using a specific indicator - tonne of waste. The criteria include the following aspects:

- Economic aspect - specific capital costs;

- Technological aspects - specific energy consumption and specific water consumption;

- Aspect of impact on climate change - specific $\mathrm{CO}_{2}$ emissions.

The resulting numbers are then converted into equal units so that they can be evaluated. In the second entry section of data, these data are inserted into the matrix and converted into numbers 1 to 5 , where 1 is the lowest valuation and 5 is the highest. In this case, if the costs are very high, then they can be estimated by 1 , but if they are relatively lower than the high cost, then with a higher valuation, for example 4. The lowest costs can even be estimated by 5 .

Then, the data is normalized with weight values, and the distance is calculated from the maximum and minimum values or the distance from the ideal. The normalization method is used to normalize the criteria.

$$
r_{a i}=\frac{x_{a i}}{\sqrt{\sum_{a=1}^{n} x_{a i}^{2}}}
$$

where

$\begin{array}{ll}a & \text { Product; } \\ i & \text { Criterion; } \\ r & \text { Normalized value. }\end{array}$

And further, the normalized results are recalculated based on the weight of each criterion. The weight of each criterion indicates how important it is or which of the criteria is decisive, less important and which is the least important.

$$
v_{a i}=w_{i} \cdot r_{a i}
$$

where

w Weight;

$v \quad$ Weighted value.

The weighted results are taken into account to determine the variation of ideal (maximum) and non-ideal (minimum) value. Each weighed indicator is compared with its corresponding maximum and minimum values. The sum of the squares of the difference between the maximum value of each alternative criteria is used to determine the total distance of the alternative to the ideal solution.

$$
d_{a}^{+}={\sqrt{\sum\left(v_{i}^{+}-v_{a i}\right)}}^{2}
$$

and 


$$
d_{a}^{-}={\sqrt{\left(v_{i}^{-}-v_{a i}\right)}}^{2},
$$

where

$d^{+}{ }_{a} \quad$ Distance to ideal solution;

$d^{-}{ }_{a} \quad$ Distance to non-ideal solution.

After this is followed by the calculation of relative proximity, where the relative proximity of each alternative to the ideal solution is calculated.

$$
C_{a}=\frac{d_{a}^{-}}{d_{a}^{+}+d_{a}^{-}},
$$

where

$C_{a} \quad$ Relative proximity to ideal solution.

This ratio is always between 0 and 1 . If the result is closer to 1 , the product is more sustainable.

After making the calculations, the third step is the result. The TOPSIS method can be used to find out which of the alternatives is the most advantageous and the most disadvantageous alternative.

\section{RESUlts}

Four product groups based on different manufacturing techniques have been selected for analysis and compared to each other.

Table 1 summarizes data from various literature sources on selected technological methods and products:

- Cellulose nanocrystals (CNC) and cellulose nanofibers (CNF) [14]-[18];

- Egg packaging [2], [13];

- Reusable paper [10], [11], [13];

- Cardboard [10], [13].

Indicators are based on how much investment, electricity, and water are needed for recycling paper waste products, as well as data on how many $\mathrm{CO}_{2}$ emissions are produced in the production process. Indicators were selected by the importance and the impact on environment and the main raw materials for the provision of processes. Amount of the indicators were found in various literature sources.

Egg packing consumes $285 \mathrm{kWh} / \mathrm{t}_{\text {waste }}, 23.4$ water $\mathrm{m}^{3} / \mathrm{t}$ and $3095.1 \mathrm{EUR} / \mathrm{t}$ and $148.77 \mathrm{tCO}_{2}$ is produced. Recycled paper production consumes $7276.2 \mathrm{EUR} / \mathrm{t}, 670 \mathrm{kWh} / \mathrm{t}_{\mathrm{waste}}$ and 24 water $\mathrm{m}^{3} / \mathrm{t}$, as well $349.74 \mathrm{tCO}_{2}$ is produced, but cardboard production requires $3040.8 \mathrm{EUR} / \mathrm{t}, 280 \mathrm{kWh} / \mathrm{t}_{\text {waste }}$ and $22.4 \mathrm{~m}^{3} / \mathrm{t}$ water, $164.16 \mathrm{tCO}_{2}$ is produced. 
TABLE 1. MUlTi-CRITERIA MATRIX

\begin{tabular}{lllll}
\hline $\begin{array}{l}\text { Method of technology. Products of } \\
\text { recycled paper }\end{array}$ & $\begin{array}{l}\text { Necessary } \\
\text { investments, } \\
\text { EUR/t } \mathrm{t}_{\text {waste }}\end{array}$ & $\begin{array}{l}\text { Energy } \\
\text { consumption, } \\
\mathrm{kWh} / \mathrm{t}_{\mathrm{waste}}\end{array}$ & $\begin{array}{l}\text { Water } \\
\text { consumption, } \\
\mathrm{m}^{3} / \mathrm{t}_{\mathrm{waste}}\end{array}$ & $\begin{array}{l}\text { Climate } \\
\text { impact, } \\
\mathrm{t}_{\mathrm{CO} 2} / \mathrm{t}_{\text {waste }}\end{array}$ \\
\hline $\begin{array}{l}\text { CNC/CNF production (produced from } \\
\text { recycled sludge without deinking) }\end{array}$ & 534 & 865 & 6 & 624 \\
$\begin{array}{l}\text { Egg packing } \\
\text { Reusable paper }\end{array}$ & 3095 & 285 & 23 & 148 \\
Cardboard & 7276 & 670 & 24 & 350 \\
\hline
\end{tabular}

The data in Table 1 are modified so that all products are characterized by the same indicators. As it can be seen from the values of the indicators, the smallest investments are needed for the production of CNC/CNF products, which, in turn, have a high specific energy consumption but low water consumption. Production of reusable paper requires large investments and high energy and water costs during operation time. All 4 criteria are equivalent to production of egg packaging and cardboard.

The results of the multi-criteria analysis are summarized in Fig. 4. Looking at the obtained results, it can be seen that the best results after the calculations are made by the product reusable paper. The second is - CNC and CNF production or the production of cellulose nanofibres and cellulose nano-crystals but the worst results are shown by the production of cardboard and egg packaging.

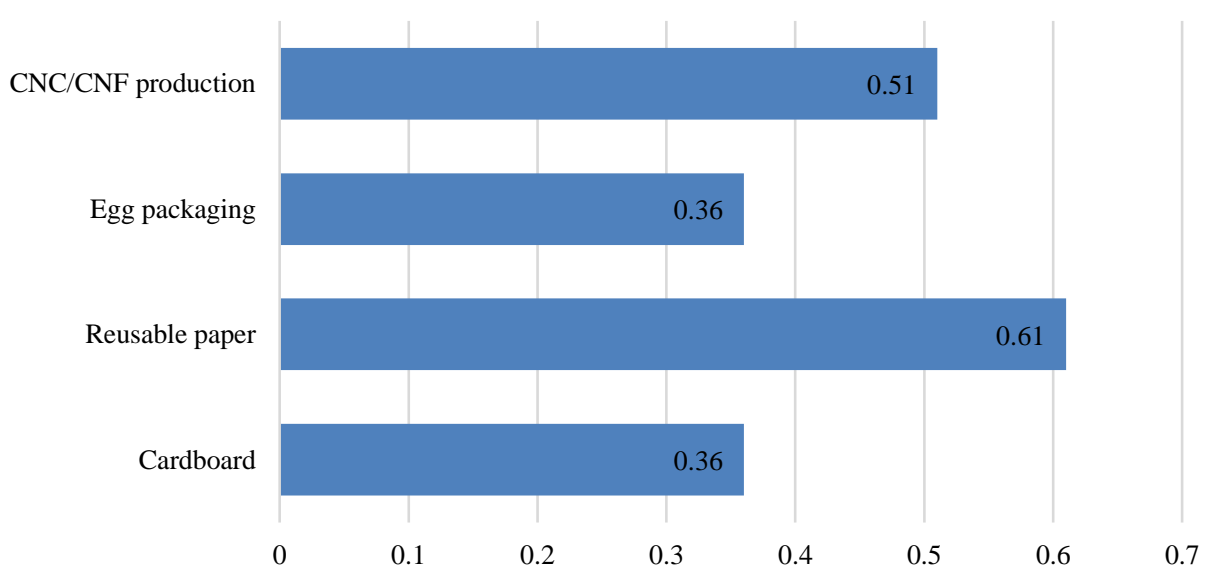

Fig. 4. Results of multi-criteria analysis.

In cases where high-quality nanoproducts are required, the raw material, which is used in the recycled paper, also needs to be deinked because the ink particles can degrade the light transmittance of the end product, as well as the light reflectance factor or the whiteness factor. Also, in recycled paper manufacturing, deinking is one of the main processes, because this process affects the final product. Also, in all of the product (cardboard, reusable paper, egg packaging, $\mathrm{CNC} / \mathrm{CNF}$ production) manufacturing water and wastewater consumption is important. The most important impact is from bleaching, but also high impact is made from waste water and water consumption. 


\section{Conclusions}

Paper waste is a good raw material for the production of various products. Technologies of paper recycling are different and there are increasing opportunities for new, innovative products due to the development of the circular economy. Waste paper is a cheap source of production of cellulose nanocrystalline, especially when the effects of ink, paint and other impurities are lower.

The results of the multi-criteria analysis showed that the production of cellulose nanofibres and cellulose nanocrystals has an advantage over egg packaging and cardboard production, but the production of reusable paper is economically viable.

Looking at the results, it can be concluded that the production of nanofibers and nanopaper of cellulose has potential in the future paper recycling market, since it can be produced from paper mill sludge from paper recycling.

\section{ACKNOWLEDGMENT}

This research is funded by the Latvian Council of Science, project "Bioresources value model (BVM)", project No. lzp2018/1-0426.

\section{REFERENCES}

[1] Zihare L., Blumberga D. Market opportunities for cellulose products from combined renewable resources. Environmental and Climate Technologies 2017:19(1):33-38. doi:10.1515/rtuect-2017-0003

[2] Pulp and Paper [Online]. [Accessed 25.11.2018]. Available: http://old.vpvb.gov.lv/ippc/bat/bat_ES1/LCelulozePapiraRupn.pdf

[3] Recycling of waste. Paper, cardboard [Online]. [Accessed 24.11.2018]. Available: http://www.varam.gov.lv/lat/darbibas_veidi/apsaimniekosana/atkritumu_veidi/?doc=6814

[4] Pasaules Dabas Fonds. 7 Steps on how to become greener [Online]. [Accessed 24.11.2018]. Available: http://www.pdf.lv/uploads/dokumenti/PDF_GreenOffice_Bookle.pdf_(in Latvian)

[5] Cheung W. M., Pachisia V. Facilitating waste paper recycling and repurposing via cost modelling of machine failure, labour availability and waste quantity. Resources, Conservation and Recycling 2015:101:34-41. doi:10.1016/j.resconrec.2015.05.011

[6] CEPI. Global forest and paper industry releases policy statement on paper recycling [Online]. [Accessed 29.11.2018]. Available: http://www.cepi.org/news/global-forest-and-paper-industry-releases-policy-statement-paper-recycling

[7] Impact REC. Recycling facts [Online]. [Accessed 9.12.2018]. Available: http://impactpaperec.eu/en/facts-figures/recycling-facts/

[8] CEPI. Recycling press release on 24 October 2018 [Online]. [Accessed 29.11.2018]. Available: http://www.cepi.org/taxonomy/term/14

[9] European Paper Recycling Council. European Declaration on paper recycling 2016-2020.

[10] Recycling of paper-waste [Online]. [Accessed 25.11.2018]. Available: http://www.jumis.lv/lv/noderiga-informacija/atkritumu-parstrade/papira-parstrade/ (in Latvian)

[11] Paperboard [Online]. [Accessed 26.11.2018]. Available: https://valorlux.lu/wp-content/uploads/2016/09/fabrication-recyclage_papier-carton_en.pdf

[12] Beverage cartoon [Online]. [Accessed 26.11.2018]. Available: https://valorlux.lu/wp-content/uploads/2016/09/fabrication-recyclage_carton-a-boisson_en.pdf

[13] Laurijssena J., et al. Paper and biomass for energy? The impact of paper recycling on energy and $\mathrm{CO}_{2}$ emissions. Resources, Conservation and Recycling 2010:54(12):1208-1218. doi:10.1016/j.resconrec.2010.03.016

[14] Adu C., Jolly M., Thaku V. K. Exploring new horizons for paper recycling: A review of biomaterials and biorefinery feedstocks derived from wastepaper. Current Opinion in Green and Sustainable Chemistry 2018:13:21-26. doi:10.1016/j.cogsc.2018.03.003

[15] Adu C., et al. Properties of cellulose nanofibre networks prepared from never-dried and dried paper mill sludge. Journal of Cleaner Production 2018:197(1):765-771. doi:10.1016/j.jclepro.2018.06.263

[16] Sudarsan J. S., et al. Papercrete brick as an alternate building material to control Environmental Pollution. IOP Conference Series Earth and Environmental Science 2017:80(1):012017. doi:10.1088/1755-1315/80/1/012017 
[17] Gomes D. G., et al. Insights into the economic viability of cellulases recycling on bioethanol production from recycled paper sludge. Bioresource Technology 2018:267:347-355. doi:10.1016/j.biortech.2018.07.056

[18] Gu H., Reiner R., Bergman R., Rudie A. LCA Study for Pilot Scale Production of Cellulose Nano Crystals (CNC) from Wood Pulp. Presented at the LCA XV Conference - A bright green future, Vancouver, Canada, 2015. 